\title{
Denitrifying and Phosphorus Removal Process and Its Affecting Factors
}

\author{
Zijin Qin ${ }^{1,}$, Liping Qiu ${ }^{1, b^{*}}$, Shoubin Zhang ${ }^{1, \mathrm{c}}$, Jiabin Wang ${ }^{1, \mathrm{~d}}$, Kang Xie Ke $^{1, \mathrm{e}}$ \\ ${ }^{1}$ School of Civil Engineering and Architecture, University of Jinan, No.336.West Road of Nan \\ Xinzhuang. Jinan. 250022, PR China

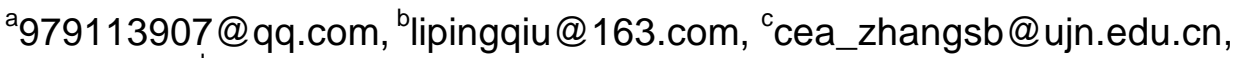

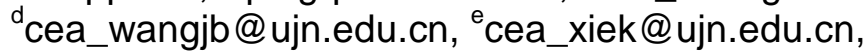 \\ * Corresponding Author
}

Keywords: denitrifying phosphorus removing process; DPBs; affecting factor

Abstract. Denitrifying phosphorus removal process is to complete domestication and enrichment of denitrifying phosphate-accumulating organisms by using anaerobic/anoxic alternate environment instead of the traditional anaerobic/aerobic environment. Then, nitrogen and phosphorus can be removed simultaneously at the same stage. This paper mainly described the mechanism of denitrifying phosphorus removal, simply introduced the denitrifying phosphorus removal process, and discussed the influencing factors of denitrifying phosphorus removal process and the prospect of its development.

\section{Introduction}

With the economy of China develop rapidly, water environment is polluted seriously, especially the water entrophication problem caused by a large use of chemical fertilizers, pesticides, and phosphorus containing detergent. Nitrogen and phosphorus are the main pollutants which cause the water entrophication, so the content of nitrogen and phosphorus in the wastewater get more and more attention. Using biotechnology to remove nitrogen and phosphorus is an effective method of treating sewage. But with the traditional biological denitrifying and phosphorus removal technology is used widely, there are still a series of contradictions and problems. Therefore, new technologies for the removing nitrogen and phosphorus and processes of high efficiency removal nitrogen and phosphorus become more and more important. Because of the advantages of saving aeration and reducing the amount of excess sludge, the technology of denitrifying phosphorus removal has become a research hotspot in recent years.

\section{Mechanism of Denitrifying Phosphorus Removal}

T. Kuba [1] showed that in anaerobic/anoxic alternative operating conditions, a class of facultative anaerobic microorganisms can be enrichment. The microorganisms can utilize $\mathrm{O}_{2}$ and $\mathrm{NO}_{3}{ }^{-}$as electron acceptor and has a similar biological metabolism with phosphorus accumulating bacteria (Paos). Anaerobic stage, HAC and other low molecular fatty acids are rapidly absorbed by denitrifying phosphorus accumulating organisms (DPBs), simultaneously the intracellular phosphate is hydrolyzed and release in the form of inorganic phosphate. By the above process DPBs produce energy ATP and glycogen fermentation reduction products $\left(\mathrm{NADH}_{2}\right)$ and synthesize a large number of PHB stored in the cell. In the anoxic phase, DPBs use $\mathrm{NO}_{3}{ }^{-}$or $\mathrm{NO}_{2}{ }^{-}$as electron acceptor to complete oxidation of PHB. The energy produced during oxidation is used to get excessive phosphorus from surrounding environment, only a small amount is used in glycogen synthesis and maintenance of life activity. In general, the amount of phosphorus uptake is much greater than that of phosphorus release, and the technology of denitrifying phosphorus removal is the use of this principle, through the discharge of excess sludge to achieve the purpose of sewage nitrogen and phosphorus removal. 


\section{The Affecting Factors of Denitrifying Phosphorus Removal}

Sludge retention time The sludge age (SRT) reflects the basic characteristics of the growth state, the growth condition and the generation period of microorganisms in the activated sludge system. The growth characteristics of the organisms, the degradation of the organic matters and the growth of the sludge were measured by the age of sludge. When the sludge age is too short, with the sludge discharge, DBPs will be gradually eliminated. When the sludge age is too long, that will make it aging, system can not reach a good effect of nitrogen and phosphorus removal.The single sludge system, nitrifying bacteria and DPBs existed in the same system. It is essential that SRT must simultaneously be considered to reach the requirements of nitrification and phosphorus removal. While in the two sludge system, the nitrifying bacteria and DPBs were in two independent systems. Therefore, only the requirements of their respective need should to be considered.

Ma fang et al.[2] used anaerobic/anoxic sequencing batch reactor (A/A SBR) to investigate the effects of sludge retention time on phosphorus removal system performance. The effect of phosphorus removal was sensitive to the change of sludge age, and the sludge age was too low or too high, which was not conducive to the stable operation of system. When the sludge age was $18 \mathrm{~d}$, it was the best combining point to maintain the concentration of sludge and the effect of phosphorus removal. However, there are also studies that show the effect of denitrifying phosphorus removal in the system was increased with the increase of the sludge age.when SRT was $12 \mathrm{~d}$ or $15 \mathrm{~d}$, carbon source required for removal of nitrogen and phosphorus was less than $8 \mathrm{~d}$ of sludge age. So the long sludge age can save the carbon source and this process is suitable for low $\mathrm{C} / \mathrm{N}$ ratio wastewater [3].

Therefore, determination of the optimum SRT of the denitrifying phosphorus removal system should be based on the inflow quality, process flow and running Requirements.

Dissolved oxygen In the process of denitrifying phosphorus removal, it is very important to control anaerobic conditions for phosphorus release. Only in absolute anaerobic environment, dissolved COD can be changed to PHB stored in the cell through fully release phosphorus. In the anaerobic stage, high DO inhibit the release of phosphorus and the synthesis of PHB, which affect the excessive absorption of phosphorus in the anoxic phase. Meanwhile it is easy to promote the growth of non phosphorus accumulating organisms which compete with DPBs for organic compounds to inhibit PHB synthesis. In anoxic stage, DO is too high, it will lead to competition between $\mathrm{O}_{2}$ and $\mathrm{NO}_{3}{ }^{-} \cdot \mathrm{O}_{2}$ will replace $\mathrm{NO}_{3}{ }^{-}$ as an electron acceptor. Thus, the effect of denitrifying and phosphorus removal is not good. At the same time, researchers have found that DO is too high, the competition ability of PAOs is stronger than DPBs. Along with the alternation of generations, the DPB will be eliminated in the system. So, In order to achieve a good effect of denitrifying and phosphorus removal, dissolved oxygen in the system needs to be strictly controlled.

$\mathbf{N O}_{3}{ }^{-}, \mathbf{N O}_{2}{ }^{-}$Ekama et al. [4] did some research about traditional denitrifying and phosphorus removal process. They believed that the degree of anoxic phosphorus uptake may be related to $\mathrm{NO}_{3}{ }^{-}$ loading in the anoxic tank. In the anaerobic stage high concentrations of $\mathrm{NO}_{3}{ }^{-}$can induce denitrification, which caused the concentration of nitrate nitrogen in anoxic phase was too low. And effect of denitrifying and phosphorus removal reduced. Phosphorus was removed in the aerobic stage. Over time, PAOs gradually become the dominant species, and DPBs will gradually be eliminated in the system.

Wang Hui et al. [5] studied on the effect of influent nitrate concentration on the process of denitrifying and phosphorus removal in an A/A SBR. The consumption of nitrate and the removal of positive phosphorus by the denitrifying phosphorus removal bacteria were obviously linear. Meanwhile phenomenon of nitrite accumulation occurred in denitrifying process. Nitrite accumulation peak concentration with continuous adding nitrate time growth decreased. This feed mode of nitrate nitrogen is more conducive to the removal efficiency of nitrogen and phosphorus.

Now, it has been widely recognized that $\mathrm{NO}_{3}{ }^{-}$and $\mathrm{O}_{2}$ as the electron acceptor for biological phosphorus removal, but there is a controversy about whether $\mathrm{NO}_{2}{ }^{-}$can be used as the electron acceptor for biological phosphorus removal. 
Some researchers believed that the low concentration of nitrate nitrogen can be used as the electron acceptor of the phosphorus accumulating bacteria, but the total phosphorus uptake and phosphorus uptake rate were significantly lower than that of nitrate nitrogen as electron acceptor [6]. And the high concentration of nitrite nitrogen can inhibit the activity of the phosphorus accumulating organisms. There are also data showed that under suitable conditions, after acclimation DPBs can use $\mathrm{NO}_{2}{ }^{-}$as electron acceptor to denitrifying phosphorus-uptake, and phosphorus absorption capacity increased gradually. At present, it has been reported that, in the lab scale experiment, after acclimation sludge can achieve good effect through the short-cut denitrifying dephosphatation [7].

In addition to the above factors in the process of denitrifying and phosphorus removal, other factors also need to be consided in the process of operation such as hydraulic retention time, $\mathrm{PH}$, mixed liquid suspended solids concentration, carbon source category, temperature and so on.

\section{Denitrifying Phosphorus Removal Process}

The characteristics of the denitrifying phosphorus removal bacteria will provide a shortcut to biological nitrogen and phosphorus removal process. So scholars have done a lot of researches not only in the mechanism of denitrify phosphorus removal, but also in the processes of denitrifying phosphorus removal. From the aspect of process study, the process of denitrifying and phosphorus removal is mainly divided into two types, single sludge and two-sludge. Single stage sludge system, in which nitrifying bacteria, DPBs and other heterotrophic bacteria grow in the form of mixture and suspension at the same time, sequentially by anaerobic, anoxic and aerobic three environment. And in the two-stage sludge system, DPBs and nitrifying bacteria independently exist in specific reactor.

Single sludge system BCFS process is based on the development of UCT technology [8]. The process is composed of anaerobic pool, contact pool, anoxic tank, mixed pool and aerobic pool, which also consists of three cycles. This kind of environment provides the favorable living conditions for DPBs. Studies have shown that BCFs process can run continuously and maintain the stability of effluent quality. The average concentrations of TP and TN in effluent were less than $0.2 \mathrm{mg} / \mathrm{L}$ and $5 \mathrm{mg} / \mathrm{L}$, respectively. At present, there were more than 10 upgrade or new sewage treatment plants which treat sewage using this process. But in the actual operation, it was found that the low $\mathrm{C} / \mathrm{P}$ ratio and high sludge age have a bad effect on the removal of phosphorus.

Two-Sludge System Currently, the typical two-sludge system is Dephanox technology and $\mathrm{A}^{2} \mathrm{NSBR}$ technology. Dephanox process evolved from the Wanner process, and had nitrification sludge backflow and denitrifying phosphorus removal sludge backflow at the same time [9]. The PHB was the denitrifying carbon source in the anaerobic sludge. The process not only solve the competition problem between denitrifying bacteria and phosphorus accumulating bacteria for organic substrate , but also solve the sludge age problem that generation cycle of the nitrifying bacteria is longer and generation cycle of poly phosphate bacteria is short. Therefore, it has the characteristics of low energy consumption, low sludge production and low COD consumption. However, a large number of studies show that this process is easily influenced by the N/P ratio of influent, and it is not easy to control. $\mathrm{A}^{2} \mathrm{NSBR}$ process is a two-sludge system composed of anaerobic/anoxic SBR $\left(\mathrm{A}^{2} \mathrm{SBR}\right)$ and nitrification SBR (NSBR). The function of $A^{2} S B R$ is to remove the COD and denitrifying phosphorus removal; the conversion of ammonia nitrogen to nitrate occurred in NSBR. The activated sludge of the two reactors is completely independent. The simultaneous removal of nitrogen and phosphorus can be achieved by the exchange of the respective supernatant.

\section{Conclusions}

About the mechanism, bacteria, affecting factors of denitrifying and phosphorus removal, scholars had made some achievements. As characteristics of denitrifying phosphorus removal technology, such as reducing the cost of wastewater treatment of low $\mathrm{C} / \mathrm{N}$ ratio and good nitrogen and phosphorus removal efficiency, denitrifying phosphorus removal technology has been applicable to current transformation of the city sewage treatment plant. In addition, because of the difficulty of DBPs in pure culture, the study of denitrifying phosphorus accumulating bacteria remains to be further. The 
structure, spatial distribution and functional relationship of the bacteria population can be revealed in depth through dynamic tracking of functional flora of the denitrifying and phosphorus removal system by enzymology and molecular biology technology, which will become a hot research topic in the future.

\section{Acknowledgements}

This study was partly supported by National Natural Science Foundation of China (51278225), Shandong Provincial Natural Science Foundation, China (ZR2013EEQ007, ZR2015EM021).

\section{References}

[1] T. Kuba, G. Smolders, M.C.M.V Loosdrecht, et al: Waterence \& Technology Vol. 27(1993), p.241.

[2] Chunli Wang, Fang Ma, Hui Liu, et al: Journal of Northeast Agricultural University Vol.38 (2007), p.637. In Chinese.

[3] Weifeng $\mathrm{Xu}, Y$ Yinguang Chen,Fang Zhang: Environmental Science Vol.28 (2007), p.1693. In Chinese.

[4] G.A.Ekama, M.C.Wentzel: Water Science \& Technology Vol.39 (1999), p.69.

[5] Hui Wang, Yanliang Shen: Chinese Journal of Environmental Engineering Vol.3 (2009), p.977. In Chinese.

[6] Meinhold J, Arnold E, Isaacs S: Water Research Vol.33 (1999), p.1871.

[7] Xuguang Tang, Shuying Wang, Jingqian Zhang: China Water \& Wastewater Vol. 25 (2009), p.29. In Chinese.

[8] M.C.M.V Loosdrecht, F.A.Brandse, A.C.D.Vries: Water Science \& Technology Vol.37 (1998), p.209.

[9] Bortone G, Malaspina F, Stante L, et al:Water Science \& Technology Vol.30 (1994), p.303. 